\title{
Oral treatment for constitutional delay of growth and puberty in boys: a randomised trial of an anabolic steroid or testosterone undecanoate
}

\author{
A Albanese, G D Kewley, A Long, K N Pearl, D G Robins, R Stanhope
}

\begin{abstract}
Thirty three boys (mean 14.6 years old, range $12 \cdot 8-16 \cdot 2$ years) with constitutional delay of growth and puberty were randomised into two groups to determine which form of oral treatment would give the better anthropometric response. The two drugs were administered by mouth (one tablet/day) for a mean of 3.5 months (range 3-7 months). At randomisation, 17 boys received testosterone undecanoate (40 $\mathrm{mg} /$ day) and 16 oxandrolone $(2 \cdot 5$ mg/day). At the start of treatment they were prepubertal or in early puberty, their height SD score was -1.97 in boys treated with testosterone and -2.21 in those treated with oxandrolone, and their growth rates were 4.3 and $4.2 \mathrm{~cm} /$ year respectively. Both sex steroid and anabolic steroid treatments induced a significant growth acceleration in all patients except four (three treated with testosterone and one with oxandrolone). When treated with the alternative sex steroid, all four non-responders had a significant anthropometric response. In all boys the induced growth acceleration was sustained when treatment was interrupted. There was no significant difference in the induced growth spurt and bone maturation between the two groups. Spontaneous progress into puberty was achieved in all boys with an increase in testicular volume from a mean of 4.6 to 8.5 $\mathrm{ml}$. The rate of development in secondary sexual characteristics was also similar in the two groups. These data suggest that oral testosterone and oxandrolone are equally effective in the treatment of growth delay in boys with constitutional delay of growth and puberty.

(Arch Dis Child 1994; 71: 315-317)
\end{abstract}

Low doses of anabolic steroids ${ }^{1}$ or testosterone $\mathrm{e}^{2}$ have been used to improve the short term

Clinical data from 33 boys with CDGP at presentation, divided in two groups according to treatment received

\begin{tabular}{lccc}
\hline & $\begin{array}{l}\text { Group 1: } \\
\text { testosterone } \\
(n=17)\end{array}$ & $\begin{array}{l}\text { Group 2: } \\
\text { oxandrolone } \\
(n=16)\end{array}$ & p Value \\
\hline Mean (range) chronological age (years) & $14 \cdot 5(13 \cdot 0-16 \cdot 2)$ & $14 \cdot 6(12 \cdot 8-15 \cdot 8)$ & $>0.05$ \\
Mean (SD) height SD score & $-1.97(0 \cdot 4)$ & $-2 \cdot 21(0 \cdot 7)$ & $>0.05$ \\
Mean (SD) growth rate (cm/year) & $4 \cdot 3(1 \cdot 7)$ & $4 \cdot 2(1 \cdot 7)$ & $>0.05$ \\
Mean (SD) bone age ('years') & $11 \cdot 2(1 \cdot 6)$ & $11 \cdot 2(1 \cdot 0)$ & $>0.05$ \\
Mean (SD) height SD score for bone age & $0 \cdot 70(1 \cdot 0)$ & $0.40(0 \cdot 9)$ & $>0.05$ \\
Mean (SD) mid-parental height SD score & $-0 \cdot 14(0 \cdot 6)$ & $-0.08(0 \cdot 2)$ & $>0.05$ \\
Mean (range) testicular volume (ml) & $4 \cdot 6(3-6)$ & $4 \cdot 6(3-8)$ & $>0.05$ \\
\hline
\end{tabular}

growth rate of boys with constitutional delay of growth and puberty (CDGP). Oxandrolone is an anabolic steroid that is mainly used $(1.25-2.5 \mathrm{mg} /$ day by mouth) for this purpose, but predominantly due to its abuse in sports medicine it does not have a product licence in the UK and it can be prescribed only on a named patient basis. Testosterone is usually administered in its depot preparation by monthly depot intramuscular injections (50-100 mg/month), although it also has a product licence in oral (undecanoate) and intramuscular (enanthate) formulations. Sex steroids $^{2}$ and anabolic steroids ${ }^{1}$ can significantly improve the short term growth rate without altering final height attainment. Nevertheless, for psychological reasons, intervention to bring forward the growth spurt may be required in patients with CDGP. The choice between the two treatments is usually age dependent, with the youngest children being treated with oxandrolone, which has less virilisating action. It is sometimes the patient's dislike of receiving injections that influences the use of oxandrolone.

There are few studies of the effectiveness of oral preparations of testosterone in inducing a growth acceleration in boys with CDGP. ${ }^{3}$ Indeed, variable absorption from the gastrointestinal tract is documented so that its effectiveness may be reduced. The aim of our study was to treat boys with CDGP with either oxandrolone or oral testosterone in a prospective randomised study to determine whether oral testosterone can be used as a valid alternative to oxandrolone in the induction of acceleration in growth.

\section{Patients and methods}

Thirty three boys with CDGP, mean age 14.6 years (range $12 \cdot 8-16 \cdot 2$ years), were randomised to receive either oxandrolone or testosterone as oral preparations and at a dose of one tablet/day to compare their effectiveness in inducing an acceleration in growth. The diagnosis of CDGP was made on clinical grounds and was retrospectively confirmed by the pattern of growth and by the spontaneous advancement through puberty. Patients with growth delay secondary to chronic diseases or corticosteroid treatment were excluded. Testosterone undecanoate $(40 \mathrm{mg} /$ day; group 1) or oxandrolone $(2.5 \mathrm{mg} /$ day; group 2$)$ was administered for mean duration of 3.5 months ( 3.3 for testosterone and $3 \cdot 7$ for oxandrolone). The two drugs were given in the evening, after the evening meal, to mimic the normal pattern 


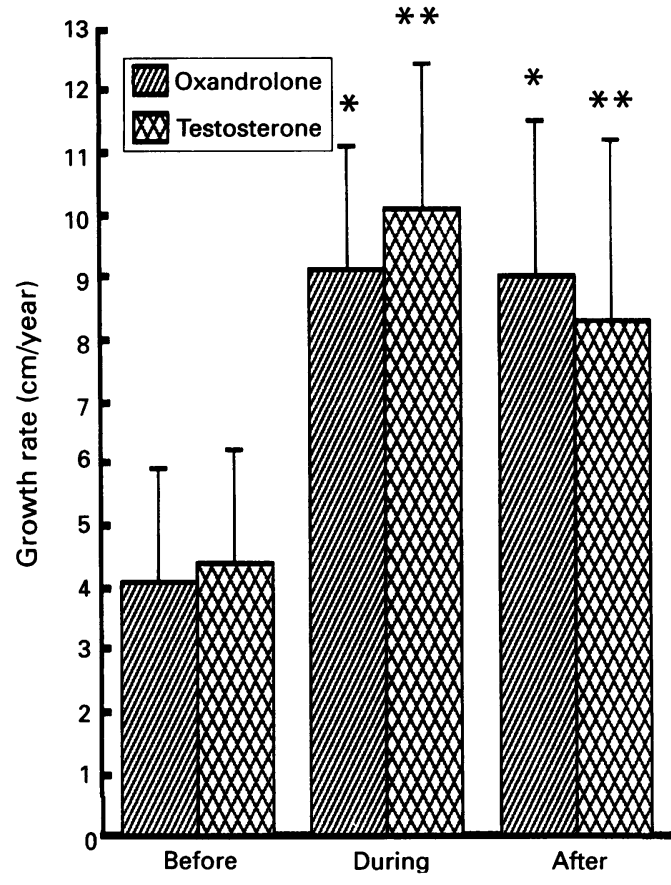

Mean growth rate in 29 boys with CDGP treated with either oral testosterone or oxandrolone in pretreatment, treatment, and post treatment periods. SDs are shown by horizontal bars; ${ }^{\star} p<0.0001 \mathrm{v}$ pretreatment value; ${ }_{\star \star} p<0.0001 \mathrm{v}$ pretreatment value.

of androgen secretion in boys in early puberty. All boys were prepubertal or at an early stage of sexual maturation with a mean testicular volume of $4.6 \mathrm{ml}$ (range 3-8 ml). Mean growth velocity was $4.2 \mathrm{~cm} /$ year during the six months before the start of treatment and bone age was delayed by 3.3 years. The table gives the anthropometric data from the patients in the two groups. No crossover of treatment between the groups was possible because the induced growth spurt was sustained when treatment stopped.

Growth assessment was by standard anthropometric techniques. ${ }^{4}$ Pubertal maturation ${ }^{5}$ and bone age assessment ${ }^{6}$ were by the methods of Tanner and coworkers. All data were expressed as a SD score relative to the normal data of Tanner et al. ${ }^{7}$ Statistical analysis was by independent and paired $t$ test and the $\chi^{2}$ test. The data are expressed as mean (SD). The study was approved by the standing committee on ethical practice of the Hospital for Sick Children, Great Ormond Street, London and written parental consent was obtained. In addition, ethics committee approval was obtained from the Crawley, Farnborough, Conquest, and Royal Surrey County hospitals.

\section{Results}

Both oral testosterone and oxandrolone induced an acceleration in growth. The mean growth velocity was $4.4(1.8) \mathrm{cm} /$ year in boys of group 1 (14 boys) and $4 \cdot 1(1 \cdot 8) \mathrm{cm} /$ year in those of group 2 ( 15 boys) for the six months before treatment. This increased to $10 \cdot 1(2 \cdot 3)$ $\mathrm{cm} /$ year $(\mathrm{p}<0.0001)$ and $9.0(2.0) \mathrm{cm} /$ year $(\mathrm{p}<0.0001)$ respectively during treatment (figure). The induced growth acceleration was sustained at a mean value of $8.3(2.9)$ $(\mathrm{p}>0.05)$ and $9.0(2.5) \mathrm{cm} /$ year $(\mathrm{p}>0.05)$ during the six months after the end of treatment. No significant difference was found in the anthropometric response to treatment between the two groups. The pattern of epiphysial maturation during treatment with sex steroids or anabolic steroids was also similar $(p>0.05)$ between the two groups, with an unaltered height SD score for bone age after treatment compared with pretreatment values. At presentation all the patients had a relatively short upper segment compared with the lower segment, which was unchanged during treatment and became significantly worse $(p<0.05)$ at the end of treatment, when growth was mainly in subischial leg length. All the boys treated with testosterone by mouth and those treated with oxandrolone presented a similar pattern of growth in response to either treatment, except four patients, three who initially received testosterone and one who received oxandrolone. The patients who did not respond to the initial three month courses of treatment with sex steroids or anabolic steroids were then transferred to the other group and treated with an additional three month course. The change of treatment was associated with a significant increase in growth rate. One of the non-responders to testosterone admitted poor compliance, but a satisfactory compliance to oxandrolone. Poor compliance was not reported by the other three non-responders. The percentage of non-responders in the two groups was not significantly different. Data from these four patients were excluded from analysis.

During treatment there was a spontaneous increase in testicular volume from a mean value of $4.6 \mathrm{ml}$ (range $3.0-6.0 \mathrm{ml}$ ) in boys in group 1 and $4.6 \mathrm{ml}$ (range $3.0-8.0 \mathrm{ml}$ ) in group 2 to $6.0 \mathrm{ml}$ (range $3.0-8.0 \mathrm{ml}$ ) and 6.2 $\mathrm{ml}$ (range $4.0-10.0 \mathrm{ml}$ ) respectively, followed by $8.0 \mathrm{ml}$ (range $4.0-12 \mathrm{ml}$ ) and $8.3 \mathrm{ml}$ (range $4 \cdot 0-12 \cdot 0 \mathrm{ml}$ ) at the end of the follow up period. There was also a progressive development in secondary sexual characteristics in the two groups with a similar rate of maturation between the two groups.

No adverse effect from the administration of either testosterone or oxandrolone was reported.

\section{Discussion}

CDGP is a disorder occurring in otherwise healthy adolescents who have short stature compared with their peers, delay in bone maturation, and delayed puberty. ${ }^{8}$ As the final height prognosis is usually appropriate for midparental centiles, one approach is to explain the diagnosis to the patient and parents and to offer reassurance. Some patients remain concerned, however, especially about their short stature, and sometimes this may result in deviant behaviour and severe psychological distress. Therapeutic help with the aim of bringing forward the growth spurt without a decrease in height potential can be offered to those boys with severe psychological disturbance. Short term treatment with either sex steroids ${ }^{2}$ or anabolic ${ }^{1}$ steroids can induce a 
growth spurt which is sustained when treatment is interrupted and becomes indistinguishable from the spontaneous growth spurt of puberty. The usual form of treatment is either a monthly intramuscular injection of depot testosterone or oral daily administration of oxandrolone. Although the former has a product licence the latter can be prescribed only on a named patient basis in the UK. There is also a testosterone preparation given by mouth (testosterone undecanoate) which has a product licence for use in androgen deficiency. We consider that boys with CDGP have transient androgen deficiency/ insufficiency. There are few data available on the effectiveness of oral testosterone in boys with CDGP, however, particularly with regard to irregular absorption. ${ }^{3}$

Our data show that oral testosterone or oxandrolone appear to be equally effective in inducing and sustaining a growth acceleration in boys with CDGP. Indeed, a similar result was found not only in growth acceleration but in bone maturation and sexual development. As testosterone has a greater virilisating action than oxandrolone, a course of treatment with testosterone would have been expected to induce or advance the development of secondary sexual characteristics. This was not found in our study, however, probably due to the small number of patients, the short duration of treatment, and perhaps poor absorption of oral testosterone. Spontaneous development in testicular volume was seen in all patients and this confirmed the diagnosis of CDGP, as well as indicating that neither treatment suppressed the hypothalamo-pituitary-gonadal axis. The induced growth acceleration occurred at too early a stage of sexual maturation to be due to the spontaneous pubertal growth spurt. Indeed, a pubertal growth spurt usually occurs in boys when a $10 \mathrm{ml}$ testicular volume is attained. ${ }^{9}$
Four of 33 patients did not respond to their initial treatment. The distribution of these non-responders among the two groups was similar. When they were transferred into the other group, however, they showed a significant growth spurt. One of these patients admitted poor compliance to the initial treatment, and we believe that this is the most common reason for a poor growth response to sex steroids or anabolic steroids. One advantage of intramuscular depot testosterone is that a record can be kept of when treatment is administered and this aids the assessment of compliance.

In conclusion, we have shown that oral testosterone (testosterone undecanoate) is an alternative to oxandrolone when oral treatment is required for boys with CDGP. In the UK this has the advantage of prescribing a drug which has a product licence. The two drugs induce a growth spurt of similar magnitude, which is sustained when treatment is interrupted.

1 Joss EE, Schmidt HA, Zuppinger ZA. Oxandrolone in constitutionally delayed growth, a longitudinal study up to final height. ff Clin Endocrinol Metab 1989; 69: 1109-15.

2 Wilson DM, Kei J, Hintz RL, Rosenfeld GG. Effects of testosterone therapy for pubertal delay. Am $\mathrm{f}$ Dis Child 1988; 142: 96-9.

3 Butler GE, Sellar RE, Walker RF, Hendry M, Kelnar CJH Oral testosterone undecanoate in the management of delayed puberty in boys: pharmacokinetics and effects on sexual maturation and growth. $\mathcal{f}$ Clin Endocrinol Metab 1992; 75: 37-44.

4 Brook CGD. Growth assessment in childhood and adolescence. Oxford: Blackwell, 1982.

5 Marshall WA, Tanner JM. Variations in the pattern of pubertal changes in boys. Arch Dis Child 1970; 45: 13-23.

6 Tanner JM, Whitehouse RH, Cameron N, Marshall WA Healy MJR, Goldstein H. Assessment of skeletal maturity and Healy MJR, Goldstein H. Assessment of skeletal maturity and
prediction of adult height (TW2 method). 2nd Ed. London: Academic Press, 1983.

7 Tanner JM, Whitehouse RH, Takaishi M. Standards from birth to maturity for height, weight, height velocity and weight velocity: British children 1965 Part II. Arch Dis Child 1966; 41: 613-35.

8 Prader A. Delayed adolescence. Clin Endocrinol Metab 1975; 4: 143-55.

9 Papadimitriou A, Wacharasindhu S, Pearl K, Preece MA, Stanhope $R$. Treatment of constitutional growth delay in prepubertal boys with a prolonged course of low-dose prepubertal boys with a prolonged course 